\title{
WOMEN CONSUMER PREFERENCES FOR SOCIALLY RESPONSIBLE FOOD PRODUCTION ATTRIBUTES: EVIDENCE FROM URBAN SUPERMARKET SETTING IN THE ANURADHAPURA DISTRICT
}

\author{
H. M. T. K. Herath, J. M. M. Udugama and U. K. Jayasinghe-Mudalige
}

\begin{abstract}
This study assesses the consumer preferences towards "socially responsible production of food" in the context of urban women consumers in Anuradhapura District. The empirical analysis focuses on whether women consumers accept certain "alterations" made to three major food products, including: (1) "Hormone Injected" Chicken; (2) "Pasteurized" Milk, and (3) "Genetically-Modified" Soya Meat, and further, how much they are willing-to-pay for such products as a premium. A series of Dichotomous-Choice Contingency Valuation questions were formulated, which elicits consumer willingness-to-pay for such products, by taking into account of certain motivational factors, including: (a) health; (b) labeling; (c) packaging, and (4) animal welfare. These were included in a structured questionnaire together with other questions to explore consumer motivational and demographic characteristics influencing their choices. The questionnaire was administrated with 500 randomly selected consumers visiting major supermarkets in the Anuradhapura city during May - June 2010. The Stated Preference models characterized by the Principle Component Analysis Technique were employed to assess the relative strengths of consumer preferences and motivation to purchase these products. The outcome of analysis implies that consumer expectations on food firms' "ethical conduct in production", the "level offood quality" and their "anxieties over the food risks" were increased progressively in the recent past and that had an impact on their food purchasing behavior and consumption patterns. The results imply that remaining food firms and potential entrants into the market should consider catering their client-base with socially responsible food products to be competitive in the market.
\end{abstract}

Keywords: Food marketing and business, Consumer behavior, Food safety and quality, Socially responsible food production

\section{INTRODUCTION}

Economic theory suggests that, in a perfectly competitive market, consumers make consumption decisions with 'full information' about product attributes; thus, a rational consumer tends to choose foods that maximize his/her utility. In the real world, however, numerous food safety information problems exist, which complicate the process of consumer decision-making on purchasing of

food products. Consumers may, in their dayto-day life, may not well informed about the level of food-borne illness risks involved with the food products they consume; perhaps, these pathogens are "not visible" to the naked eye. Raw meat and poultry products, for example, contain levels of microbial pathogens that are potentially harmful. Aside from some rather obvious indications (e.g., unpleasant odor or 
discoloration, both of which are more likely to be caused by non-pathogenic spoilage micro-organisms), there are no "convenient" and "economic" ways and means available for consumers to determine the health risks associated with food (Antle, 1995).

Markets may, however, not generate efficient level of risk information mainly because the producers may lack of incentives to do so due to public good characteristics associated with information. It was reported that the private incentives to generate information are less than socially optimal, because information is a public good that can be repeatedly transferred regardless of its producer's assent or compensation. Indeed, the real incentive for a producer may be to 'conceal' information as it is difficult to 'sell' consumers dangerous products. The imperfections in providing information in food markets apply to some extent in all markets and to a greater extent in others, and consequently, the consumers are put in a disadvantaged position. When consumers do not have equal access to information about products and markets, where information about market opportunities and production technology is not equally available to all producers, or where factors of production are restricted in their ability to move in response to such information, market forces will not allocate efficiently and the economy will produce below its capacity (Viscusi, 1989).

If information about product quality before the purchase is imperfect, consumers may be put in a position of buying a product whose quality is uncertain. Although firms could offer a product with a higher price to reflect its higher quality, at the same time, it raises a theoretical problem too, i.e. if firms to communicate quality to consumers use price, then how will the process of competition work while consumers seek out the lowest price? However, as long as a substantial number of knowledgeable consumers in the market demand a high quality product and they are willing to pay for it, we may argue that the higher price is sufficient to ensure that nonperformance results in a greater loss than a gain (Stiglitz, 1989).

Previous studies that examined consumers' willingness to pay (WTP) for food products have, in general, confined to use three stated preference methods, including: (1) hedonic prices; (2) contingent valuation, and (3) conjoint analysis/choice experiments (Akaichi et al., 2012). Researchers have now turned to the use experimental auctions, which use real products and exchange of real money for this purpose in the recent past (Fox et al., (2002); Dickinson and Baily (2002); Soler etal.,(2002); Lusk et al., (2004); Kassardjian et al., (2005); Rousu et al., (2005); Shaw et al., (2006) and Alfnes (2009). In the experimental auctions, a participant can incur real costs if he or she deviates from the equilibrium strategy, which then provides him/her an incentive to bid his/ her real values. The outcome of such analyses in the context of developed countries, overall, suggest that the money that a consumer may be willing to pay as a 'premium' for improved safety to offset the potential negative effects of food safety hazards can be "substantial"; for example, for a consumer in the United States, it could range from a premium of 15 to 30 percent per meal to reduce their risk of becoming ill from meat.

The food economics literature suggests that consumers perceive on a given product as "sets of attributes", which, in fact, determines the performance of that product and its utility. As a result, consumers do not necessarily look at the product as a whole as they decide on whether to purchase the product or not, but on these attributes individually or collectively (Jayasinghe-Mudalige, 2005). These attributes can be either Concrete product attributes (e.g. price, taste, smell) or Abstract attributes (e.g. safety, trustworthiness). The major product quality attribute subsets concerning food products, according to Caswell 
(2007) include: (1) food safety (food borne pathogens, pesticide residues, food additives and veterinary residues); (2) nutrition (fat content, calories, fiber, sodium, vitamins and minerals); (3) value (appearance and taste); (4) package (package material labeling and other information provided), and (5) process (animal welfare, use of genetically modified foods) attributes.

More often than not, consumers have certain expectations about the product that are based on these product attributes or, in other words, quality cues. In the context of current food markets, the products with "socially responsible" production attributes have been developed and marketed in response to a wide range of public concerns. In fact, many of these attributes relate to environmental and/ or social concerns, for example fair-trade for fair treatment of workers, humane treatment of domestic animals, minimizing the distance food is transported, conservation of wildlife and biodiversity (McCluskey et al., 2009).

Though the consumer concerns about various food quality attributes mentioned above were of interest of food economists in developed countries over the last two decades, empirical analyses focusing on the same issue in the context of developing countries were limited to a small number and very few from the Sri Lankan consumer perspective (Kariyawasam et al., 2007; Lakni and Jayasinghe-Mudalige, 2010). Thus, there exists a huge gap in food economics literature with regard to consumer concerns about production of socially responsible food products and extent to which characteristics of a consumer such as age, gender and level of education have an impact on the consumer behavior.

In this shed of light, the purpose of this study was to assess empirically the Sri Lankan consumers' preferences towards socially responsible production of food. More specifically, it tried to investigate empirically whether consumers accept certain "alterations" made to three major food products available in the marketplace, i.e.: (1) "Hormone-treated" Chicken; (2) "Pasteurized" Milk, and (3) "Genetically-Modified" Soya Meat, and in turn, how much they are willing to pay to purchase such products over the standard products of the same available in the marketplace. It evaluates the special case of perceptions of women consumers who used to purchase such products from the urban supermarket setting in the Anuradhapura District of Sri Lanka.

\section{MATERIALS AND METHODS}

The rationale for selecting the three products specified above is as follows. With regard to (1) above, consumers, in general, perceive that poultry food available in the market are adulterated with "growth hormones" so that chicken fed with them are growing fast, and ultimately, are ended up with a body weight that is greater than the normal weight of a bird. Therefore, consumer may assume this process to be a "socially irresponsible" type of food production, and consequent to that, they do not want to pay a higher premium for such products. On the same argument, if consumers are in a position to distinguish such a product from those "non-treated", they may tend to place a lower bid on those treated products.

In relation to (2) above, it is a well known fact that fresh milk is pasteurized to make the product very safe and durable. We may, thus, consider that "pasteurization" of milk as a "socially responsible" food production and consumers are willing-to-pay a premium for such a product. Regarding the product type (3), consumers may not possess a sound knowledge with regard to the processes involved with production of "genetically modified" food, and as a result, they may be divided over the potential benefits and costs of consuming such products. Those who perceive that they are not safe may consider them as 
"socially irresponsible" food production and not to pay a higher premium, while others may be remained neutral or pay a high premium considering the quality of final product.

The empirical analysis followed a two-step procedure: (1) assess the extent to which certain factors can motivate woman consumers' decisions with regard to purchasing of socially responsible food products, and (2) elicit their willingness-to-pay towards purchasing of such products. The methods used in this process to develop analytical frameworks and to collect and analyze data are discussed, in turn.

\section{Motivational factors guiding consumer food purchasing decisions}

Numerous factors can motivate a consumer to decide on her purchasing of a food product available in the market. Some of these may be attributed to demographics of a consumer (e.g. age, education, income), while others can be attributed to various subsets of food quality (Lakni and Jayasinghe-Mudalige, 2009)

While the demographics of consumers are observable or can be assessed objectively, a complete and precise understanding on consumer behavior with regard to different attributes of food quality is made difficult by, amongst the others, prevalence of different ethical characteristics that are appealing to different individuals depending on their personal attitudes and values (Antle, 1999). To minimize such issues dealt with unobservability of consumer preferences and behavioral patterns, we have, therefore, narrowed down the focus of this study to four major motivational factors commonly cited in literature that govern consumer decision making process on purchasing of food items.

The motivational factors considered in the analysis, thus, include: (a) "Health" concerns of a consumer resulting from her perceptions on level of food safety, nutrition, purity, preservatives and additives of a given food product; (b) "Labeling" of food product to spells out the key information with respect to, for example, the calorie level, date of expiry, composition and ingredients etc. (i.e. search characterizes); (c) "Packaging" material/s; its size and durability etc. that can augment the products shelf life, storage etc., and (d) "Animal welfare", i.e. whether food manufacturers follow the standard procedures and ethical guidelines in raring, feeding, slaughtering and processing of animals. The fact that all these motivational factors are directly unobservable; thus, it is difficult to evaluate them by means of a single variable (Hair et al., 2006) has led us to express each factor in terms of a number of different attitudinal statements explaining the underline phenomenon. A set of attitudinal statements ( $n=13$ ) were formulated following the steps used in previous empirical assessments on similar studies (Henson and Traill, 2000). Further, the expertise knowledge of a cross section of academics comprised of food and agricultural economists, nutritionists and food technologists was of greater help (Table 01).

Given the fact that a more than one statement was specified to express a single motivational factor (e.g. $\mathrm{S}_{1}$ to $\mathrm{S}_{5}$ for "health" and $\mathrm{S}_{6}$ to $\mathrm{S}_{8}$ for "labeling"), there was a need to examine those statements for their Unidimensionality ${ }^{1}$. The Principle Component Analysis (PCA) - a multivariate data analysis technique proposed to reduction of data in similar cases - was applied for this purpose, where the Eigen Values and Eigen Vectors were calculated to provide for the examination of responses and to produce the weights that transform the response variables into reduced set of representative variables. The Varimax Rotation was used to create an orthogonal solution, which was the basis for the formation of the weights used (Hair et al., 2006). 
Table 01. Food quality attributes based on Caswell's classification

\begin{tabular}{|c|l|}
\hline \multicolumn{1}{|c|}{ Attribute of Quality } & \multicolumn{1}{|c|}{ Forms of the Attribute for the } \\
Case of Milk Powder
\end{tabular}

Source: Lakni and Jayasinghe-Mudalige (2010)

\section{Estimation of willingness-to-pay for socially responsible products}

The Contingent Valuation (CV) method was willingness-to-pay for the three socially employed to estimate women consumers' responsible food items listed above. The 
Double-Bounded Model specified by Hanemann et al., (1991) was employed for this purpose, especially to derive questions to elicit responses as follows. In the doublebounded model, each participant to the study was presented with two bids of which the level of $2^{\text {nd }}$ bid was contingent upon the response to the $1^{\text {st }}$ bid. The two bids, for the purpose of this analysis, were valued at: (current market price of the product \pm Rs. 10). For example, given the current market price of $1 \mathrm{~kg}$ of chicken during the period of contact was Rs. 350 it was set as the $1^{\text {st }}$ bid (i.e. $\mathrm{B}_{\mathrm{O}}$ ), and as a result, the $2^{\text {nd }}$ higher bid was set to Rs. 360 (i.e. $B_{H}$ ) and the $2^{\text {nd }}$ lower bid was at Rs. 340 (i.e. $\mathrm{B}_{\mathrm{L}}$ ).

If the response of an individual to the $1^{\text {st }}$ bid (i.e. $\mathrm{B}_{\mathrm{O}}=350$ ) was "Yes", that was an indication that the respondent in concern was willing to pay Rs. 350 to purchase the product specified (i.e. chicken treated with hormones). The same respondent was, then, presented with the $2^{\text {nd }}$ higher bid $\left(\mathrm{B}_{\mathrm{H}}=360\right)$ to see whether she likes to pay more money to purchase the same product with a higher premium. Conversely, if the individual's respond to the $1^{\text {st }}$ bid was "No", it was an indication that she does not like to pay that amount to purchase the specified product. She was, in turn, presented with the $2^{\text {nd }}$ lower bid $\left(\mathrm{B}_{\mathrm{L}}\right)$ (Figure 01).

The four possible recurrent responses to the bidding scenario, as shown in Figure 1, are: [(A) "Yes" to both bids; (B) "Yes" followed by "No"; (C) "No" followed by a "Yes", and (D) "No" to both bids]. Accordingly, a range was isolated in which the respondent's true willingness to pay lies placing it into one of the following four intervals, respectively from [(A) to (D)] scenarios depicted above: $\left[\left(\mathrm{B}_{\mathrm{H}}\right.\right.$, $+\infty),\left(B_{H}, B_{O}\right),\left(B_{O}, B_{L}\right),\left(B_{L},-\infty\right)$. Further, under the current market price of Rs. 350 for chicken, the four intervals would be: [(Rs. 360 to $+\infty$ ), (Rs. 350 to 360 ), (Rs. 340 to 350 ), (Rs. 340 to $-\infty)$ ].

The outcome of this bidding process generates a response variable with four options (i.e. A to D), which, of course for the purpose of this study, represents four different consumer groups preferred one of those four options for a given product (e.g. chicken) and can, therefore, be specified as the integer values from 1 to 4 for further statistical analysis. Given the categorical nature of this response, we can apply a Multinomial Logistic Regression for this response variable with four options (i.e. 1 to 4), which is in the form of:

$W T P=\alpha+\gamma^{\prime} Z+\varepsilon$

where, $W T P=$ willingness to pay; $Z=$ column vector of the demographic (observable) characteristics of respondents; $e=$ random variable, and $\alpha$ and $\gamma=$ parameters to be estimated. Once the demographic and motivational factors of consumers were taken into account, the empirical representation of equation (1) shall be written in the form of:

$W_{m}=\alpha_{m}+\Sigma \gamma_{m n}{ }^{*}$ Demographics $_{n}+\Sigma \gamma_{m n} *$ Motivational factors ${ }_{n}+\varepsilon_{m n}$

where, $m=m^{\text {th }}$ product in $M$ [M $\equiv\{$ Hormonetreated chicken, Pasteurized milk and Genetically-modified soya meat\}.

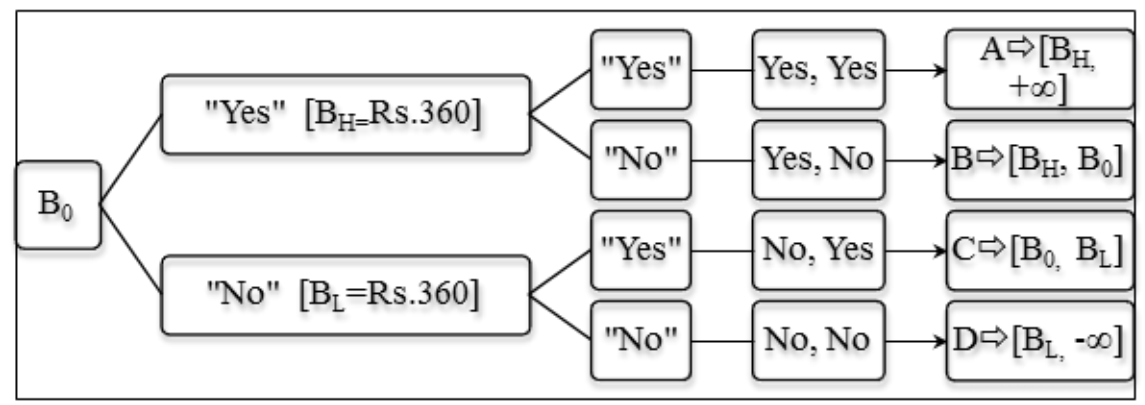

Figure 01. Bidding procedure 
The "Statistical Package for Social Sciences" (SPSS) [version 16] was used to carry out the PCA and Multinomial Logit Regression analysis.

\section{Collection and Analysis of Data}

A pre-tested $(\mathrm{n}=15)$ structured questionnaire, which includes specific questions to gather information with regard to demographics of consumers as well as the set of attitudinal statements to assess motivational factors, was administered with a sample of 500 women who visited large-scale supermarkets located in the Anuradhapura city limits to purchase their day-to-day grocery needs during May to June 2010. A convenience sample was selected based on the time taken to introduce the study, get the consent of respondent to participate or refused, and if agreed, time taken to fill the questionnaire. Nearly, 50 percent of contacts were, however, refused citing various reasons (e.g. busy, shy, lack of interest and/ or knowledge on these issues etc.), but the maximum effort was taken to obtain a random sample by contacting the every $5^{\text {th }}$ woman entered into the supermarket.

Once the consent of respondent was obtained by elaborating the method of collection of data and approximate time takes to complete the survey material (i.e. about 10 minutes), she was given with an option, i.e. to participate to study straightforward and then do grocery, or do grocery first and participate to the study before she reaches to the counter for payments, where a vast majority was agreed to the later, which was, of course, the preferred option of the researchers since it facilitates observing the purchasing patterns of consumers. A care was taken to have minimum interruptions to the regular activities in the supermarket, and thanks to the management of supermarkets, a convenient location was arranged for the purpose of recording data.
With regard to the statements explaining motivational factors, each respondent was asked to rate each statement on a five-point Likert-scale by taking into account of the extent to which he/she agrees with the phenomenon explained under that particular statement. The scores provided by a respondent to respective statements of a given motivational factor (e.g. 5 statements for "health" and 3 for "labeling") were used to derive an additive index, where the summation of scores of all statements was divided by the maximum potential score that the respondent can obtain (i.e. 5 x $5=25$ for "health" in the five-point likert scale and $3 \mathrm{x}$ 5 for "labeling") to normalize the value of the index. With this normalization, the values of the index for a given respondent, thus, ranges from 0 to 1 , where 0 reflects the least concern over the motivational factor, and 1 on the other extreme, reflects the highest concern on it (Udugama et al., 2011).

\section{RESULTS AND DISCUSSION}

\section{Descriptive Statistics of the Sample}

The majority of respondents in the sample was within the age category of $31-45$ years and was educated up to Advanced level. Nearly 70 percent of the respondents in the sample were having children. The majority of respondents (37\%) belonged to the income category of Rs. 15,001 - Rs. 25,000. To facilitate an analysis based on demographic characteristics of respondents, they were classified into nine categories based on the age (i.e. A1 = below 30 years; $\mathrm{A} 2=>30$ and $<45$ years; $\mathrm{A} 3=>45$ years) and level of education (i.e. $\mathrm{E} 1=$ up to $\mathrm{O} / \mathrm{L} ; \mathrm{E} 2=$ up to $\mathrm{A} / \mathrm{L} ; \mathrm{E} 3$ = beyond $\mathrm{A} / \mathrm{L}$ ) (Figure 02 ), and the value of additive index explained above was estimated for each motivational factor for these nine consumer groups. 


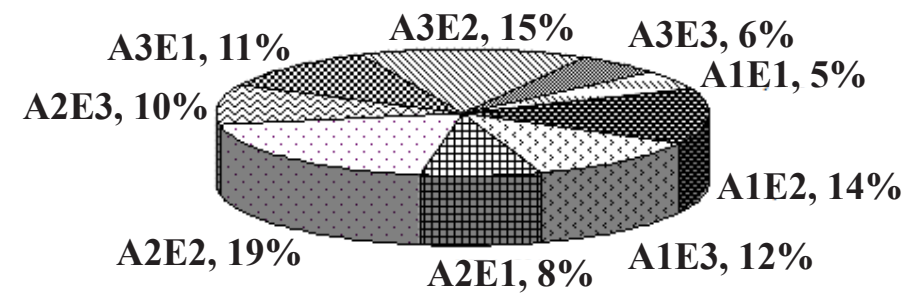

Figure 02. Percentage of Resondents in each demographic group

\section{Outcome of PCA}

Table 02 reports the outcome of PCA. It shows into a single component confirming that all the statements in four motivational unidimensionality. factors, except $S_{1}$ in health factor, loaded

Table 02. Set of statements used and the rotated component matrix

\begin{tabular}{|c|c|c|c|}
\hline & Questions (All on 5 point Likert scale) & Type $^{*}$ & Component \\
\hline \multicolumn{4}{|c|}{ Health } \\
\hline $\mathrm{S}_{1}$ & I would like to buy hormone injected chicken & $\underline{\mathrm{A}}$ & - \\
\hline $\mathrm{S}_{2}$ & I'm concerned about the way of pasteurizing the milk & $\underline{\mathrm{A}}$ & 0.329 \\
\hline $\mathrm{S}_{3}$ & $\begin{array}{l}\text { I'm concerned whether that company or grocery provides optimum } \\
\text { storage conditions for foods }\end{array}$ & $\underline{\mathrm{A}}$ & 0.510 \\
\hline $\mathrm{S}_{4}$ & I avoid foods containing nitrates and preservatives & $\underline{\mathrm{A}}$ & 0.615 \\
\hline $\mathrm{S}_{5}$ & I worry that there are harmful chemicals in my food & $\underline{\mathrm{A}}$ & 0.735 \\
\hline \multicolumn{4}{|c|}{ Labeling } \\
\hline $\mathrm{S}_{6}$ & I believe information include in the label & $\underline{\mathrm{A}}$ & 0.721 \\
\hline $\mathrm{S}_{7}$ & $\begin{array}{l}\text { I'm concerned about the expired and manufactured date, men- } \\
\text { tioned. }\end{array}$ & $\underline{\mathrm{A}}$ & 0.736 \\
\hline $\mathrm{S}_{8}$ & I'm concerned about ingredients listed in the label & $\underline{\mathrm{A}}$ & 0.341 \\
\hline \multicolumn{4}{|c|}{ Packaging } \\
\hline $\mathrm{S}_{9}$ & I buy products which have high quality packaging & $\underline{\mathrm{A}}$ & 0.708 \\
\hline $\mathrm{S}_{10}$ & I buy products which have high attractive packaging material & $\underline{\mathrm{A}}$ & 0.708 \\
\hline \multicolumn{4}{|c|}{ Animal Welfare } \\
\hline $\mathrm{S}_{11}$ & $\begin{array}{l}\text { I'm concerned about the way of transporting the animal before } \\
\text { slaughtering }\end{array}$ & $\underline{\mathrm{A}}$ & 0.807 \\
\hline $\mathrm{S}_{12}$ & I'm concerned about the way of slaughtering the animal & $\underline{\mathrm{A}}$ & 0.814 \\
\hline $\mathrm{S}_{13}$ & I'm concerned about the welfare of domestic farm animals & $\underline{\mathrm{A}}$ & 0.193 \\
\hline
\end{tabular}

SN $=$ Statement number.

Extraction Method: Principal Component Analysis.

Rotation Method: Varimax with Kaiser Normalization.

$\underline{A}^{*}$ type responses: Strongly Agree, Agree, Neither Agree or Disagree, Disagree, Strongly Disagree. 
The scores given to these were, in turn, used to derive the index, and the values of which obtained for the four motivational factors for the nine consumers groups are illustrated in Figure 03.

It highlights that, on average, irrespective of the age or level of education, the women consumers paid the most attention on the "Labeling" attribute as they believed information in the label to be a critical factor affecting their purchase. However, irrespective of the demographic characteristics, all consumers paid relatively less attention on Health and Animal welfare attributes. Nevertheless, this does not imply the fact that they did not have a significant concern as the mean index value of for all four attributes, including health and animal welfare attributes were higher than 0.5 highlighting that they perceive all four attributes to be "important" affecting their purchasing behavior. Where the impact of motivational factors on the individual food product is of concern, the level of response to the bids highlights the fact that, the majority of respondents were in favor of the bid category $\mathrm{D}$ indicating that irrespective of the product type, they were initially not willing to pay the market price nor were they willing to pay a price within the range of Rs. 10 (Figure 04).

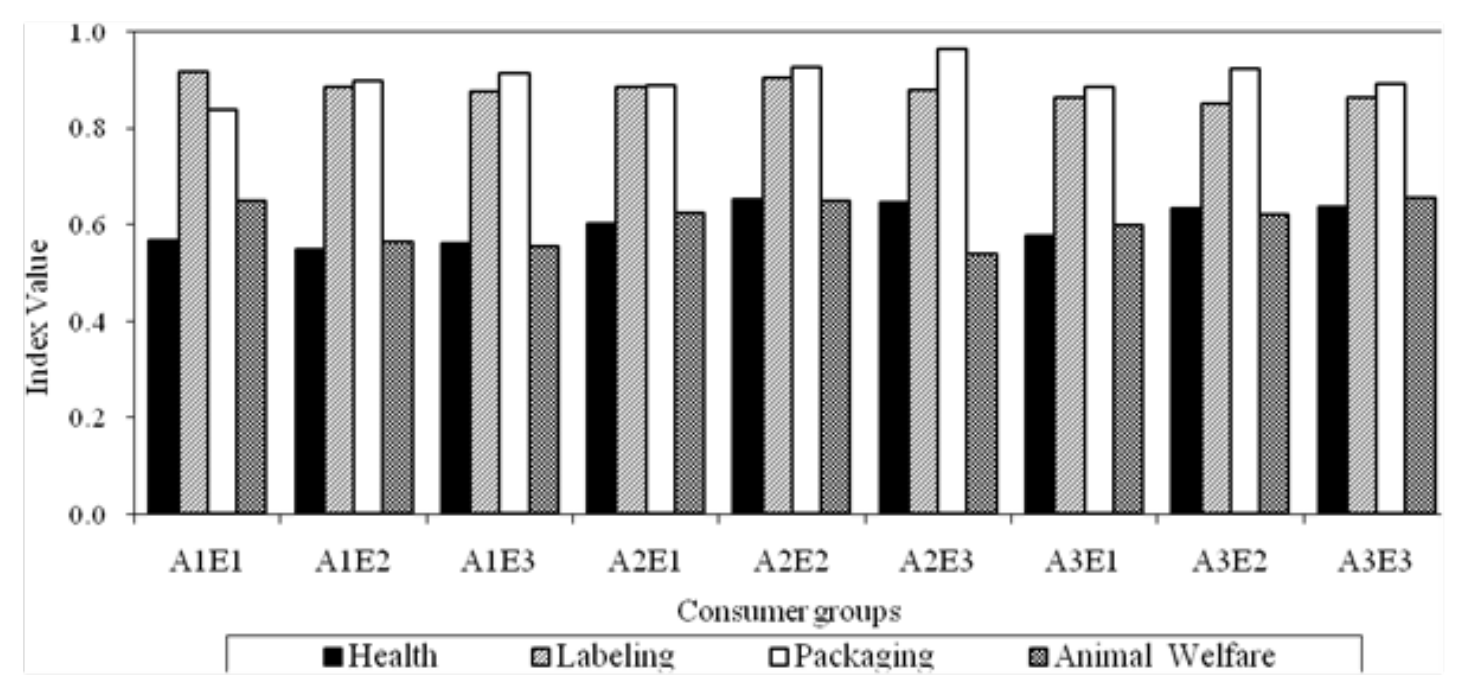

Figure 03. Perception of each consumer group on motivational factors

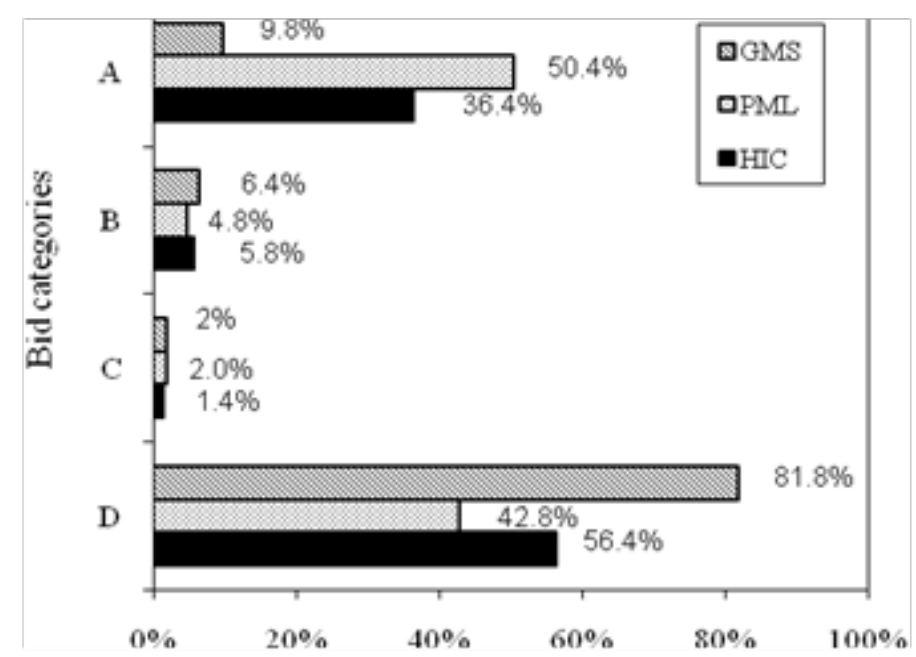

Note: $B D 1=(-8, B L), B D 2=(B L, B 0), B D 3=(B 0, B H)$ and $B D 4=(B H,+8)$;

$H I C=$ Hormone Injected Chicken, $P M L=$ Pasteurized Milk and GMS = GM Soya Meat .

Figure 04. Percentage of consumers on bid categories 
This perception was highest with regard to GMS, as they were on the belief that the term 'genetically modified' indicated modifications in food resulting in adverse health effects which was in turn reflected by their purchasing behavior. On the other hand, those who were willing to pay the market price were willing to pay a higher price for both HIC and PL, but were reluctant to pay a higher price for GMS with only 10 percent of respondents stating in favor of a higher bid. With respect to each product, the majority was not willing to pay neither the market price nor a price lower on the perception that injection of hormones and genetically modified soya meat has long term health effects on the consumers. As all respondents were aware of the nature of the three products of concern, we were on the assumption that the respondents were relatively informed to respond to the bids.
Interestingly, majority (51\%) preferred the bid category A on the belief that, milk being a perishable product the more value added it was, the more consumable it would be due to its increased shelf life and time of storage.

\section{Outcome of the Multinomial Logit Regression (MNLR)}

Where demographic factors are of concern, although most factors did not show a statistically significant impact on the purchase, the presence of children had a consistently statistically significant effect on bid category $\mathrm{BD}_{1}$ in relation to bid category $\mathrm{BD}_{4}$ with respect to purchase of the three products implying that the women consumers having children pay more attention on the price when buying HIC and GMS as opposed to PML (Table 03).

Table 03. Outcome of the Contingency Valuation Model

\begin{tabular}{|c|c|c|c|c|c|c|c|c|c|}
\hline & \multicolumn{3}{|c|}{$\begin{array}{c}\text { Hormone Injected } \\
\text { Chicken } \\
\text { (HIC) }\end{array}$} & \multicolumn{3}{|c|}{$\begin{array}{c}\text { Pasteurized Milk } \\
\text { (PML) }\end{array}$} & \multicolumn{3}{|c|}{$\begin{array}{c}\text { GM Soya Meat } \\
\text { (GMS) }\end{array}$} \\
\hline & $\mathrm{BD}_{1}$ & $\mathrm{BD}_{2}$ & $\mathrm{BD}_{3}$ & $\mathrm{BD}_{1}$ & $\mathrm{BD}_{2}$ & $\mathrm{BD}_{3}$ & $\mathrm{BD}_{3}$ & $\mathrm{BD}_{1}$ & $\mathrm{BD}_{3}$ \\
\hline Intercept & 0.45 & $13.61^{* *}$ & 0.11 & 0.45 & $13.61^{* *}$ & 1.11 & 0.11 & 0.45 & 4.21 \\
\hline Age & 0.00 & -0.03 & 0.00 & 0.00 & -0.03 & 0.00 & 0.00 & 0.00 & 0.01 \\
\hline Children & $0.49^{*}$ & -1.06 & -0.14 & $0.49^{*}$ & -1.06 & 0.34 & -0.14 & $0.49^{*}$ & 0.21 \\
\hline$\geq \mathrm{O} / \mathrm{L}$ & 0.46 & -0.69 & $1.26^{* *}$ & 0.46 & -0.69 & -0.47 & $1.26^{* *}$ & 0.46 & 0.29 \\
\hline $\mathrm{A} / \mathrm{L}$ & 0.11 & 0.49 & 0.51 & 0.11 & 0.49 & -0.59 & 0.51 & 0.11 & -0.61 \\
\hline$>15,000$ & 0.17 & $-17.81^{*}$ & $-1.38^{* *}$ & 0.17 & $-17.81^{*}$ & -0.00 & $-1.38^{* *}$ & 0.17 & $-1.70^{*}$ \\
\hline $15-25,000$ & 0.13 & -19.36 & -0.85 & 0.13 & -19.36 & 0.01 & -0.85 & 0.13 & -0.70 \\
\hline Health & 1.20 & -17.89 & -9.25 & 1.20 & -17.89 & -3.58 & -9.25 & 1.20 & -12.26 \\
\hline Labeling & -6.33 & 55.08 & 9.25 & -6.33 & 55.08 & 2.61 & 9.25 & -6.33 & -12.93 \\
\hline Packaging & -0.60 & -4.11 & $-15.43^{* *}$ & -0.60 & -4.11 & $-19.51^{*}$ & $-15.43^{* *}$ & -0.60 & -9.00 \\
\hline $\begin{array}{l}\text { Animal } \\
\text { Welfare }\end{array}$ & -3.78 & -13.46 & -8.12 & -3.78 & -13.46 & -11.44 & -8.12 & -3.78 & -5.01 \\
\hline
\end{tabular}

Note: *Significant at 5\% level; **Significant at $10 \%$ level.

Hormone injected chicken (HIC), Pasteurized milk (PML), GM Soya (GMS).

$B D_{1}, B D_{2}$ and $B D_{3}$ are bid categories and all coefficients were obtained reference to $B D_{4}$ category of bi 
It was evident that compared to the consumers with a tertiary education, the fact that a female consumer had a secondary education had an insignificant contribution on willingness to pay for the three products. Undoubtedly, income has a positive impact as the consumers with a monthly income over Rs. 15,000 were seen to have a significant impact on the purchase of all products more importantly on the third bid category (category $\mathrm{C}$ ) implying that they were willing to pay lower than the existing market price. Considering the motivational factors, packaging was the only factor having a considerably significant impact on the purchasing of HIC and PML, while it showed no significant impact on the purchase of GMS.

Paying more attention on the packaging, in relation to each bid category where the consumers were not willing to pay the market price or a price lower, they were in favor of paying a lower price for both hormone injected chicken and pasteurized milk. Although "Labeling" represented the most consistently influential factor score in the model, it was statistically insignificant for $\mathrm{BD}_{1}$ and $\mathrm{BD}_{2}$ for $\mathrm{HIC}$ and $\mathrm{BD}_{3}$ for GMS. The remaining factors were generally significant for specific product related to the factor in question apart from the "Health" factor. However, it is evident that consumers rely more on the label of a product irrespective of their WTP category.

\section{CONCLUSIONS}

There is an evident change in the food consumption pattern of consumers around the globe and no exception for Sri Lanka resulting from their primary concerns on health and environment and increased knowledge levels. At the same time, with increasing opportunity cost of time, i.e. people are "busier" than ever before, increases the incentive to optimize purchase of food and pay more attention on the quality of food products. Exploring this phenomenon, this particular study revealed that the highest consumer WTP range was recorded for Pasteurized Milk followed by Hormone Injected Chicken, while GM Soya Meat represents the lowest WTP among the three products as majority of consumers were WTP a price lower than the market price. The demographic factors, the presence of children and education up to secondary education, higher income have a positive impact on their WTP showing an inverse relationship with the lower income group of the urban women consumers. Interestingly, though the awareness and concern on motivational factors were adequate, these factors did not significantly influence the purchasing behavior and WTP other than the "Labeling" attribute as a majority of the urban women consumers rely on and were sensitive towards the information they received from the label of a product during purchase in relation to other motivational factors.

The results suggest the importance of awareness of people on certain product attributes specially among the women dwelling in an urban setting in making purchase decision, in fact in relation to the price. It further implies that consumer expectations on food firms' "ethical conduct in production", the "level of food quality" and their "anxieties over the food risks" were increased progressively in the recent past and that it had an impact on their food purchasing behavior and consumption patterns. To the extent that these findings apply more generally, it is evident that remaining food firms and potential entrants into the market should consider catering their client-base with socially responsible food products; however, further economic research is warranted to understand the dynamics of side-by-side economics to cater a clientele. 


\section{REFERENCES}

Akaichi, F., Nayga, R. M. and Gil, J. M. (2012). Assessing Consumers' Willingness to Pay for Different Units of Organic Milk: Evidence from Multiunit Auctions. Canadian Journal of Agricultural Economics, doi: 10.1111/j.1744-7976.2012.01254.

Alfnes, F. (2009). Valuing Product Attributes in Vickrey Auctions When Market Substitutes are Available. European Review of Agricultural Economics, 36, pp. 133-143.

Antle, J. M. (1995). Choice and Efficiency in Food Safety Policy. The AEI Press: Washington DC.

Antle, J. M. (1999). Benefits and Costs of Food Safety Regulation. Food Policy, 24:pp. 605623.

Dickinson, D. L. and Baily, D. (2002). Meat Traceability: Are U. S. Consumers Willing to Pay for it?. Journal of Agricultural and Resource Economics, 27, pp. 348-364.

Caswell, J. A. (2007). Study on Regulatory Reform and the Ago-food Sector. Directorate for Food, Agriculture and Fisheries, Organization for Economic Co-operation and Development. Paris Cedex 16.

Fox, J. A., Hayes D. and Shogren, J. (2002). Consumer Preferences for Food Irradiation: How Favorable and Unfavorable Descriptions Affect Preferences for Irradiated Pork in Experimental Auction. Journal of Risk and Uncertainty, 24, pp. 75-95.

Hair, J. F., R. E. Anderson, R. L. Tatham, and Black, W. C. (2006). Multivariate Data Analysis with Readings, New Jersey: Prentice Hall.

Hanemann, M. W., Loomis, J. and Kanninen, B. J. (1991). Statistical Efficiency of DoubleBounded Dichotomous Choice Contingent Valuation. Agricultural Economics, 73(4), pp. 1255-1263.

Henson, S., and Traill, B. (2000). Measuring perceived performance of the food system and consumer food-related welfare. Journal of Agricultural Economics, 51(3), pp. 388-404.

Jayasinghe-Mudalige, U. K. (2005). Provision of an Appropriate Level of Food Safety to Consumers: Who Takes the Accountability?. Accountancy Journal, 3 pp. 1-8.

Kariyawasam, S., U. K. Jayasinghe-Mudalige and Weerahewa J. (2007). Use of Caswell's Classification on Food Quality Attributes to Assess Consumer Preferences towards Fresh Milk in Tetra-Packed Containers. Journal of Agricultural Sciences, 3(1), pp. 43-54.

Kassardjian, E., Gamble, J., Gunson, A., and Jaeger, S. R. (2005). A New Approach to Elicit Consumers' Willingness to Purchase Genetically Modified Food Apples. British Food Journal, 107, pp. 541-555.

Lakni, W. A. K. I. and Jayasinghe-Mudalige, U. K. (2009). Customer-Defined Quality of Food: An Empirical Investigation Based on Kano Analytical Methods for Milk Powder. Journal of Agricultural Sciences, 4(2), pp. 45-58. 
Lusk, J., House, L., Valli, C., Jaeger, S., Moore, M., Morrow, B., and Traill, B. (2004). Effect of information about Benefits of Biotechnology on Consumer Acceptance of Genetically Modified Food: Evidence from Experimental Auctions in United States, England, and France. European Review of Agricultural Economics, 31, pp. 179-204.

McCluskey, J. J., C. A. Durham, C. A and Horn, B. P. (2009). Consumer Preferences for Socially Responsible Production Attributes Across Food Products. Agricultural and Resource Economics, 38(3), pp. 345-356.

Rousu, M., Monchuk, D. C., Shogren, J. F. and Kosa, K. M. (2005). Consumer Willingness to Pay for "Second Generation" Genetically Engineered Products and The Role of Marketing Information. Journal of Agricultural and Applied Economics, 37, pp. 647-657.

Shaw, W. D., Nayga, R. M. and Silva, A. (2006). Health Benefits and Uncertainty: An Experimental Analysis of The Effect of Risk Presentation on Auction Bids for a Healthful Product. Economics Bulletin, 4, pp. 1-8.

Soler, F., Gil, J. M. and Sánchez, M. (2002). Consumers' Acceptability of Organic Food in Spain: Results From An Experimental Auction Market. British Food Journal, 104, pp. 670-687.

Stiglitz, J. E. (1989). 'The development of financial markets for economic development', lecture presented at a conference by the Vargas Foundation, 'The Economic Reconstruction of Latin America', Rio de Janeiro.

Udugama, J. M. M., U. K. Jayasinghe-Mudalige and Anjalee, G. H. I. (2011). Impact of Environmental Altruism on Adoption of Solid Waste Management Practices in the Firm: Case of Agri-Food Processing Sector in Sri Lanka. Journal of Agricultural Sciences, 6(1), pp. 32-44.

Viscusi, W. K. (1989). Prospective Reference Theory: Towards an Explanation of the Paradoxes. Journal of Risk and Uncertainty, 2, pp. 235-264. 